\title{
Governo Eletrônico e seu relacionamento com o desenvolvimento econômico e humano: um estudo comparativo internacional
}

\author{
Lamartine Vieira Braga \\ Fundação Getúlio Vargas (FGV)
}

Ricardo Corrêa Gomes

Universidade de Brasilia (UnB)

Embora alguns relatórios e trabalhos científicos associem características do governo eletrônico com o desenvolvimento econômico e humano, estudos empíricos que comprovem essas correlações são exíguos, evidenciando uma lacuna que este artigo buscou preencher. Para tanto, lançou-se mão de uma abordagem dedutiva e objetiva da qual derivou uma estratégia de trabalho de natureza quantitativa. Em suma, constatou-se que os melhores índices de governo eletrônico encontram-se concentrados no continente europeu, em países de alta renda per capita, detentores dos mais elevados níveis de desenvolvimento econômico e humano, embora haja exceções importantes, como Coreia do Sul e Cingapura. Verificou-se, ainda, que a correlação mais significativa com a renda per capita se deu com a variável E-Government Development Index (EGDI) e a menor com Participação Eletrônica. Ademais, constatou-se que as associações mais significativas, no que se refere aos indicadores de desenvolvimento humano, se dão com o Índice de Desenvolvimento Humano Ajustado à Desigualdade (IDH-D).

Palavras-chave: governo eletrônico, tecnologia da informação, modernização administrativa, desenvolvimento econômico

[Artigo recebido em fevereiro de 2014. Versão final em março de 2015.] 
Gobierno electrónico y su relación con el desarrollo económico y humano: um estúdio comparativo internacional

A pesar de la existencia de informes y artículos científicos relacionados con el desarrollo económico y humano, los estudios empíricos que confirman éstas correlaciones son limitados, lo que muestra la necesidad de un trabajo como el que ahora presentamos. Con ese objetivo, se utilizó una metodología deductiva y objetiva de la que derivó una estratégia de trabajo de naturaleza cuantitativa. En suma, se constató que los mejores índices de gobierno eletrónico se encuentran concentrados en el continente europeo, en países de alta renta per cápita, detentores de los más elevados niveles de desarrollo económico y humano, aunque existan excepciones importantes, como Corea del Sur y Cingapura. Se verificó, además, que la correlación más significativa con la renta per cápita se dió con la variable E-Government Development Index (EGDI) y la menor con la Participación Electrónica. Por otro lado, se constató que las asociaciones más significativas, en lo referente a los indicadores de desarrollo humano, se dan con el Índice de Desarrollo Humano Ajustado a la Desigualdad (IDH-D).

Palabras Clave: gobierno electrónico, tecnología de la información, modernización administrativa, desarrollo económico

Electronic government and its relationship to economic and human development: an international comparative research

Although several scientific papers and reports correlate features of electronic government with economic and human development, empirical studies that prove these correlations are scarce, pointing a gap that this article sought to fill. For this aiming, this research employed a deductive and objective approach from which a quantitative strategy was derived. In short, it was found that the highest rates of electronic government are concentrated in developed countries of Europe, classified as high income and very high human development, although there are important exceptions, such as South Korea and Singapore. It was also found that the most significant correlation with per capita income variables are given with E-Government Development Index (EGDI) and the least with e-participation. Moreover, it was found that the most significant associations with regard to human development indicators are given to the Inequality-adjusted Human Development Index (IHDI).

Keywords: electronic government, information technology, administrative modernization, economic development 


\section{Introdução}

O governo eletrônico emergiu, a partir da década de 1990, como uma nova e poderosa agenda de pesquisa (Alonso; FernedA; BragA, 2011; MisuracA, 2009; Sending; NeumanN, 2006). De acordo com Heeks e Bailur (2007), trata-se de uma esfera conceitual marcadamente interdisciplinar, passando pela Ciência Política, Psicologia, Ciência da Informação, Administração Pública, entre outras. Medaglia (2012), por seu turno, o descreve como envolvendo uma interseção de ciências da informação e da computação, ciências política, social e comportamental, além de programas de governo, atos administrativos e produção legislativa.

Há dez anos, Löfstedt (2005) afirmava que o governo eletrônico era um campo do conhecimento que ainda permanecia em seu estágio exploratório, algo que, somado ao seu largo espectro de abrangência, evidenciava o imperativo de estudos teóricos e, sobretudo, empíricos. Passados dez anos, Bannister e Connolly (2015), revendo a literatura da última década, constatam que, apesar dos avanços significativos no aperfeiçoamento de uma teoria deficiente, o campo de estudo ainda carece de estudos descritivos.

Tais constatações justificam a realização do presente trabalho, cujo objetivo é analisar-se o relacionamento entre governo eletrônico e desenvolvimento econômico e humano em função de variáveis específicas.

Para tanto, a partir de uma abordagem dedutiva (BRYMAN, 2008) e objetiva (BURRelL; Morgan, 1979), foi delineada uma estratégia de pesquisa composta por três etapas: revisão de literatura, verificação empírica dos pressupostos básicos por intermédio do exame de dados, e explicitação das conclusões e recomendações. Além disso, optou-se pela realização de um corte de caráter transversal, limitando o escopo do estudo ao momento presente.

Uma abordagem dedutiva e objetiva, como é o caso deste artigo, geralmente está associada com uma metodologia de pesquisa quantitativa, a qual se caracteriza pela quantificação no processo de coleta e análise de dados. Essa etapa se subdivide em duas fases. A primeira se refere à pesquisa de campo, que, no caso particular, correspondeu à coleta de dados secundários oriundos de três instituições: Organização das Nações Unidas (ONU), Programa das Nações Unidas para o Desenvolvimento (PNUD), e Banco Mundial. A segunda fase corresponde ao emprego da técnica estatística apropriada, que, no presente estudo, foi o método de análise bivariada denominado de correlação linear de Pearson.

Este documento está organizado da seguinte forma: além desta seção introdutória, na seção seguinte o referencial teórico de estudo é abordado de forma sucinta. A terceira seção trata da explicitação da metodologia de pesquisa, em que 
se justifica a seleção de dados e a escolha das variáveis de pesquisa. Em seguida, ocorre a apresentação e a discussão dos resultados do trabalho. Por fim, são tecidas as considerações finais e recomendações de trabalhos futuros.

\section{Governo eletrônico}

Desde o final da década de 1990, há um amplo debate no campo da administração pública sobre qual seria a extensão da mudança em organizações governamentais pela adoção de tecnologias de informação e comunicação (TIC). Evidências recentes sugerem que as estruturas do Estado sofrerão alterações consideráveis na medida em que os agentes públicos passarem a utilizar as novas TIC para redesenhar seus programas, serviços, organizações e redes de cooperação (BRAGA, 2007, 2009, 2011; Bussell, 2011; Deakins et al., 2010; Ferneda; Alonso; Braga, 2011; Goldfinch; Gauld; BaldWIN, 2011; Medaglia, 2012; Tripathi; Gupta; Bhattacharya, 2012; WEERAKKODY et al., 2012).

A origem do termo governo eletrônico remonta a meados da década de 1990, na conjuntura de emergência da internet comercial e de modelos como New Public Management; Westminster Model; Reinventing Government; e National Performance Review. De acordo com Pina, Torres e Royo (2007), nessa época, o termo significava, simplesmente, a transferência das experiências de e-business do setor privado para o setor público.

Uma das primeiras referências à expressão governo eletrônico na literatura é feita por Milward e Snyder (1996), os quais afirmam tratar-se da tecnologia usada para conectar serviços governamentais e cidadãos, eliminando ou diminuindo a necessidade desses últimos de se reportarem a um local específico ou de se aterem a determinado horário de atendimento. Como resultado, o acesso a esses serviços é, ao mesmo tempo, aumentado e facilitado.

Uma definição bastante ampla de governo eletrônico inclui todas as aplicações e plataformas de TIC usadas no setor público (ROBERTSON; VATRAPU, 2010). De forma mais restrita, refere-se ao uso da internet e da Web para disponibilizar informação e serviços aos cidadãos (UNITEd NATIONS, 2004; UNITEd NATIONS; AMERICAN SOCIETY FOR PUblic AdMINISTRATION, 2002). Essa também é a definição de Zweers (2007), segundo o qual governo eletrônico envolve a provisão ou consecução de informação, serviços ou produtos, por meios eletrônicos, por intermédio de agências governamentais, a qualquer momento e lugar, resultando em um valor adicional para todos os participantes. Governo eletrônico também pode ser visto como o uso de TIC na administração pública, combinado com mudança organizacional e novas práticas, a fim de melhorar os serviços públicos, os processos democráticos, e fortalecer o suporte às políticas públicas (EUROPEAN COMMUNITIES, 2003). 
De acordo com Stahl (2005), governo eletrônico pode ser entendido sob três aspectos da administração pública. Primeiro, sob a perspectiva das tarefas executivas, quando essas são realizadas com o auxílio de TIC, ou seja, trata-se de tarefas administrativas, relativas à melhoria de processos internos, como é o caso da automação de atividades. Segundo, o governo eletrônico pode ser entendido como a oferta de serviços públicos e de informações, cujo foco é a elaboração de políticas públicas. Terceiro, o governo eletrônico pode ser entendido sob o aspecto da interação com a sociedade, como fator de incremento à liberdade de escolha, viabilizado mecanismos de promoção da democracia.

Há um conceito segundo o qual o governo eletrônico é componente de um sistema de três dimensões (UNITEd Nations; American SOCIeTY for PUblic Administration, 2002):

- Governo eletrônico: relacionamentos interorganizacionais, incluindo coordenação e implementação de políticas públicas e disponibilização de serviços públicos eletrônicos.

- Administração eletrônica: relacionamentos intraorganizacionais, incluindo o desenvolvimento de políticas, atividades organizacionais e a gestão do conhecimento.

- Governança eletrônica: interações entre cidadãos, organizações governamentais, burocracia e políticos, aperfeiçoando o processo de formulação de políticas públicas e transformando o processo de governar.

Seguindo essa mesma linha, outros autores também separam governo eletrônico de governança eletrônica. A primeira se refere à habilitação eletrônica de todos os serviços providos pelo setor público. Já a governança eletrônica diz respeito à habilitação eletrônica de todas as outras atividades do governo, por exemplo: gestão da atividade democrática, garantia da justiça e da transparência da tomada de decisão nas instituições públicas etc. (BovaIRD, 2005; D'Agostino et al., 2011).

As dimensões supracitadas encontram-se, em grande medida, refletidas nas quatro áreas de relacionamento do governo com atores-chave da sociedade por intermédio da utilização de TIC definidas pela ONU (BRAGA; BRAGA, 2011; UNITED NATIONS, 2005):

- Relações entre governos: pela melhoria de processos internos, pela automação de tarefas rotineiras, especialmente manutenção de registros e recuperação de dados, e pela habilitação de maiores níveis de comunicação e colaboração entre membros de organizações governamentais, a despeito da localização física (organização virtual em rede).

- Relações entre governo e usuários e entre empregadores e empregados: por intermédio da oferta eletrônica de serviços. 
- Relações entre governo e cidadãos: via diversas formas de democracia digital, incluindo comunidades virtuais que facilitam a troca de informações e a mobilização política.

- Relações entre governo e empresas: por meio de oportunidades de negócios eletrônicos em áreas como aquisições de bens e serviços (e-procurement).

De acordo com Lenk e Traunmüller (2007), essas quatro áreas de relacionamento do governo espelham-se em quatro perspectivas que caracterizam o governo eletrônico: do processo, do destinatário (ou do cidadão), da cooperação e dos negócios.

As relações descritas anteriormente podem ser categorizadas da seguinte forma (UNITED NATIONS, 2003):

- B2G/G2B (business-to-government e seu reverso): transações envolvendo empresas e governo.

- G2C/C2G (government-to-consumer/citizen e seu reverso): transações envolvendo governo e consumidores finais ou cidadãos.

- G2G (government-to-government): transações entre governos.

Carter e Bélanger (2005) adicionam uma quarta categoria de relacionamento às três descritas anteriormente: G2E/E2G (government-to-employee e seu reverso): transações envolvendo governo e seus empregados.

Cabe esclarecer que, enquanto o termo governo, descrito nas categorias acima, abrange órgãos e entidades dos Poderes Executivo, Legislativo e Judiciário, o termo consumidor/cidadão, por seu turno, inclui qualquer membro da sociedade de forma ampla, ou seja, tanto indivíduos quanto organizações (UNITED NATIONS, 2003). A propósito, é digno de nota que o contexto da utilização do governo eletrônico é tão abrangente quanto seu espectro de usuários, pois envolve atores públicos, privados e não governamentais; formais e informais; pertencentes a níveis locais, nacionais e internacionais, que realizam os mais variados tipos de transações (ROBERTSON; VATRAPU, 2010).

Em função disso, Ho (2002) define governo eletrônico como um fenômeno amplo, que abrange transformações mais substanciais que a mera oferta de serviços eletrônicos. Para outros autores, trata-se da reinvenção da forma como o governo interage com suas agências, com os cidadãos, com as empresas e com outros stakeholders (BRAGA et al., 2008; DUNLEAVY et al., 2006; LENK; TRAUNMÜLLER, 2007; LÖFSTEDT, 2005; MOSSE; WHITLEY, 2009). Cuida-se de abordagens mais complexas do governo eletrônico, estendendo seu conceito a questões de governança, como o engajamento online de stakeholders no processo de debate, formulação e implementação de políticas públicas (LARSSON; GRÖNLUND, 2014; PINA; TORRES; ROYO, 2007). 
Essa visão é acompanhada por Misuraca (2009), cuja perspectiva baseia-se no neo-institucionalismo e no construtivismo social. O foco de análise concentra-se na maneira como diferentes atores-chave interagem quando da introdução de TIC, e na maneira como essas interações podem afetar as instituições e a sociedade como um todo.

Löfstedt (2005) e também Robertson e Vatrapu (2010) compartilham esse pensamento, afirmando que o governo eletrônico, pelo uso das TIC, possibilita uma melhor interação dos principais stakeholders entre si: cidadãos, políticos, agências governamentais, empresas e outras organizações.

Uma perspectiva ainda mais ampla, ainda que restrita ao campo teórico, associa o governo eletrônico, por intermédio da democratização do acesso à informação e ao conhecimento, à promoção do desenvolvimento econômico (LÖFSTEDT, 2005) e humano (UNited Nations; AMERICAN SOCIETY FOR PUblic AdMinistration, 2002). O presente trabalho adota essa perspectiva, ao mesmo tempo em que busca subsídios no campo empírico para validá-la, como será demonstrado posteriormrente.

\section{Desenvolvimento econômico e humano}

Segundo Hirschman (1981), o desenvolvimento econômico é um campo do conhecimento relativamente novo, tendo nascido como uma subdisciplina dos estudos da Economia. Segundo esse autor, no entanto, a Economia sempre the relegou um papel marginal nos processos de ascenção e declínio econômico.

Sen (1983), por seu turno, ao analisar o trabalho de Hirschman (1981), ultrapassa, no seu entendimento, uma perspectiva um tanto tradicional e limitada, afirmando tratar-se de uma disciplina que desempenha um papel central no campo do crescimento econômico de países em desenvolvimento.

Ainda de acordo com Sen (1983), a ênfase dessa nova disciplina perpassa quatro temas estratégicos, a saber: industrialização; rápida acumulação de capital; mobilização de mão de obra subempregada; e planejamento e um Estado economicamente ativo, além de vários outros temas, tais quais formação de habilidades.

Na visão de Sen (1983), tais temas encontram-se intimamente relacionados a críticas que se fazem aos modelos neoclássicos tradicionais aplicados aos países em desenvolvimento. Com efeito, a visão comtemporânea dominante acerca do desenvolvimento econômico tem seu foco em variáveis de caráter material, tais como produto nacional bruto per capita e riqueza nacional (ANAND; SEN, 2000).

A abordagem do desenvolvimento humano, por sua vez, também pode ser atribuída à literatura do campo da Economia, remontando a autores como Adam Smith, David Ricardo, Robert Malthus, Karl Marx e John Stuart Mill. 
Entretanto, deve-se destacar que, à época dos autores supracitados, a preocupação primordial residia basicamente na produção e no sucesso financeiro, ou seja: ênfase no sucesso material de forma geral em oposição ao desenvolvimento de vidas humanas como um todo.

Em suma, pode-se afirmar que o estudo do desenvolvimento humano tem como objetivo não apenas o crescimento econômico, como é o caso da abordagem do desenvolvimento econômico, mas também a capacidade de expansão das capacidades humanas e, por conseguinte, da amplitude de oportunidade de escolhas (MEHTA, 2014).

Nesse sentido se orientam os indicadores escolhidos como variáveis de estudo deste trabalho, como será mais bem detalhado na seção seguinte.

\section{Metodologia de pesquisa}

Inicialmente, cabe enfatizar que a adequada mensuração de distintos conceitos oferece as bases necessárias para a construção de estimativas mais precisas sobre o possível grau de correlação entre duas variáveis que buscam representá-los. Não obstante, governo eletrônico é um fenômeno de natureza abstrata e multidimensional que não pode ser diretamente quantificado. Ademais, o setor público não se caracteriza pela homogeneidade. A alternativa, nesses casos, é lançar mão de medidas indiretas, ou seja, indicadores.

Entretanto, devido à complexidade abrangida dentro do universo conceitual do governo eletrônico, envolvendo variadas dimensões, tais quais a tecnológica (existência de infraestrutura adequada); a política (estágio qualitativo da presença governamental na web); e a humana (acesso da população à informação e ao conhecimento), a elaboração de indicadores nessa área não é uma tarefa trivial (BhatNAGAR, 2004; CURTIN; SOMMER; VIS-SOMMER, 2004; GRöNLUND, 2002; ZWEerS, 2007). Ademais, a construção de medidas compostas, como é o caso de grande parte dos indicadores existentes sobre governo eletrônico, necessariamente envolve ponderações difíceis, geralmente feitas por experts técnicos. Posteriormente, quando ocorre a utilização dessas medidas pelos tomadores de decisão, em geral políticos, há grandes chances de não se compreender, no todo, aqueles julgamentos que deram origem ao desenho dos referidos instrumentos de avaliação (POLLITT, 2011).

Em que pesem essas dificuldades, têm sido envidados esforços a fim de se construir indicadores nessa área. Um recente estudo identificou mais de 20 pesquisas globais sobre governo eletrônico conduzidas entre os anos de 2000 a 2007, no meio das quais se destacam as realizadas pelas seguintes instituições: Accenture; Brown University; Economic Intelligence Unit; Organização para a 
Cooperação e Desenvolvimento Econômico (OCDE); ONU; Taylor Nelson Sofres; União Europeia; Waseda University; e World Economic Forum em parceria com a Harvard University (UNITED NATIONS, 2007).

Dentre essas pesquisas, a United Nations E-government Survey se sobressai por uma série de razões, entre outras, as quais justificam a sua escolha como fonte de dados secundários utilizados neste trabalho: cobertura de todos os países membros da ONU; análises mais focadas em questões importantes para os países em desenvolvimento; possibilidade de comparação de dados entre diversos países e regiões e entre diferentes intervalos temporais; e acesso fácil e gratuito à sua base de dados.

A partir desse conjunto de dados secundários, foram selecionados três indicadores para serem utilizados como variáveis para representar as dimensões do governo eletrônico: E-Government Development Index (EGDI), Serviços Online (componente do EGDI) e Participação Eletrônica. Trata-se de indicadores oriundos da pesquisa global sobre governo eletrônico realizada pela $\mathrm{ONU}^{1}$ (United Nations E-government Survey) desde 2002. Nesse primeiro ano, excepcionalmente, o trabalho foi realizado em parceria com a American Society for Public Administration (United Nations; American Society for Public Administration, 2002). As demais pesquisas foram realizadas nos anos de 2003, 2004, 2005, 2008, 2010 e 2012 (UNited NATIONS, 2003, 2004, 2005, 2008, 2010, 2012).

Esses estudos têm como objetivo fornecer indicações sobre o grau de desenvolvimento do governo eletrônico aos formuladores de políticas públicas e profissionais que atuam nessa área. De acordo com seu modelo conceitual, o EGDI é um indicador composto a partir de três dimensões: Serviços Online; Infraestrutura de Telecomunicações e Capital Humano. A dimensão Participação Eletrônica também é medida pela ONU, desde 2003, no âmbito de suas pesquisas sobre governo eletrônico, embora não integre a composição do EGDI, constituindose em um indicador suplementar. O Quadro 1, apresentado abaixo, detalha as características dos indicadores formadores do EGDI e também do indicador suplementar de participação eletrônica.

\footnotetext{
${ }^{1}$ Department of Economic and Social Affairs.
} 
Quadro 1: Características dos componentes do EGDI e do Indicador Participação Eletrônica

\begin{tabular}{|c|c|c|c|c|}
\hline Componente & $\begin{array}{c}\text { Natureza do } \\
\text { Indicador }\end{array}$ & \multicolumn{1}{|c|}{ Aspectos Considerados } & $\begin{array}{c}\text { Peso na Formação } \\
\text { do EGDI }\end{array}$ \\
\hline Serviços Online & Qualitativo & $\begin{array}{l}\text { Disponibilização de informações } \\
\text { e serviços eletrônicos de governo } \\
\text { em seis áreas: educação; saúde; } \\
\text { tributação; previdência social; } \\
\text { trabalho e meio ambiente. }\end{array}$ & $1 / 3$ \\
\hline $\begin{array}{c}\text { Infraestrutura de } \\
\text { tele- } \\
\text { comunicações }\end{array}$ & Quantitativo & $\begin{array}{l}\text { Capacidade infraestrutural de } \\
\text { conectividade de telecomunicações } \\
\text { de um determinado país no que } \\
\text { tange à disponibilização de serviços } \\
\text { eletrônicos. }\end{array}$ & $1 / 3$ \\
\hline $\begin{array}{c}\text { Capital Humano } \\
\text { Participação } \\
\text { Eletrônica }\end{array}$ & Quantitativo & $\begin{array}{l}\text { Grau de desenvolvimento social de } \\
\text { acordo com critérios adotados pela } \\
\text { área de educação. }\end{array}$ & $1 / 3$ \\
\hline Qualitativo & $\begin{array}{l}\text { Nível de utilidade de serviços } \\
\text { eletrônicos do quarto estágio (serviços } \\
\text { conectados) do primeiro componente } \\
\text { do EGDI (Serviços Online). }\end{array}$ & - \\
\hline
\end{tabular}

Fonte: Elaborado pelos autores com base em United Nations (2012).

O EGDI leva em conta tanto a capacidade quanto a disposição do setor público na implementação de TIC, considerando não somente a execução das funções de governo e a disponibilização de serviços públicos, mas também o aprimoramento da informação e do conhecimento para os cidadãos. De acordo com esse conceito, o termo capacidade representa a competência sistêmica do Estado em termos financeiros, regulatórios, administrativos, infraestruturais e humanos. Já o significado do termo disposição reside no comprometimento governamental na provisão de informações e conhecimento aos cidadãos, a fim de aumentar seu empowerment (UNITED NATIONS, 2005).

Ademais, cabe destacar que esse indicador busca compreender de uma forma ampla um fenômeno complexo, como é o caso do governo eletrônico, abrangendo aspectos tecnológicos, como características técnicas dos websites; políticos, como as estratégias nacionais de governo eletrônico; e humanos, como o nível de desenvolvimento social (UNITED NATIONS, 2004, 2005, 2010).

O primeiro componente do EGDI, o Indicador de Serviços Online, busca aferir o desempenho dos países segundo um modelo de maturidade de quatro estágios. Esse modelo assume, baseado na observação extensiva e reflexão entre experts, que os países, corriqueiramente, iniciam seu desenvolvimento com uma presença 
emergente online com websites simples, progridem para um estado aperfeiçoado, com a implantação de conteúdo multimídia e interação de duas vias, avançam para um nível transacional com vários serviços providos online e governos solicitando inputs dos cidadãos em matérias de políticas públicas, para, finalmente, alcançar um estado de rede conectada de funções integradas, com compartilhamento de dados generalizado e consulta rotineira aos cidadãos, usando redes sociais e ferramentas relacionadas (UNITED NATIONS, 2010).

Com a finalidade de se obter o conjunto de índices do indicador de serviços online, os pesquisadores acessam os principais websites governamentais de cada país, abrangendo: o portal central; o portal de serviços eletrônicos; o portal de participação eletrônica; os sítios dos Ministérios da Educação, do Trabalho, da Assistência Social, da Saúde, da Fazenda e do Meio Ambiente, quando disponíveis. Além dos pesquisadores analisarem seus conteúdos e características, os websites nacionais sofrem uma avaliação acerca dos níveis mínimos referentes à acessibilidade e conteúdos disponíveis de acordo com critérios definidos pelo Web Content Accessibility Guidelines of the World Wide Web Consortium ${ }^{2}$ (UNITED NATIONS, 2012).

O segundo componente do EGDI, denominado de Índice de Infraestrutura de Telecomunicações, é o resultado de uma média aritmética composta de cinco indicadores relativos à capacidade infraestrutural de conectividade de telecomunicações de um determinado país no que tange à disponibilização de serviços públicos eletrônicos. A relação desses indicadores é a seguinte: estimativa de usuários de internet; quantitativo de linhas de telefone fixo; quantitativo de assinantes de telefone móvel; quantitativo de assinaturas de internet fixa; e uso de internet de banda larga. A fonte primária desses dados é a International Telecommunication Union (ITU) (UNITED NATIONS, 2008; 2012).

O terceiro e último componente do EGDI, Índice de Capital Humano, é composto de uma média ponderada de dois indicadores: taxa de alfabetização de adultos (com peso de dois terços) e taxa bruta combinada do grau de matrícula nos níveis de ensino fundamental, secundário e universitário (com peso de um terço). As fontes primárias desses dados são a United Nations Educational, Scientific and Cultural Organization (UNESCO); o PNUD; e o Banco Mundial (UNITED NATIONS, 2012).

Por fim, o indicador suplementar denominado de Participação Eletrônica busca aferir a qualidade do quarto estágio (serviços conectados) do primeiro componente do EGDI (Serviços Online). Ele é obtido por meio de um questionário cujas perguntas se subdividem em três categorias focadas, respectivamente, no uso da internet

${ }^{2}$ Disponível no sítio: http://www.w3.org/TR/WCAG/. 
como facilitador: da provisão de informações dos governos aos cidadãos para fins de tomada de decisão (e-information sharing); da interação com stakeholders com o objetivo de incrementar os processos deliberativos e a participação da sociedade (e-consultation); e do engajamento dos cidadãos, favorecendo seus inputs nos processos de tomada de decisão (e-decision making) (UNITED NATIONS, 2012).

Deve-se ressaltar que, enquanto o Indicador de Serviços Online busca medir a disponibilidade de informações e de serviços eletrônicos, o Índice de Participação Eletrônica tem como objetivo aferir a qualidade e o grau de utilidade dessas informações e serviços, com a finalidade de engajar os cidadãos no processo de formulação de políticas públicas, por intermédio de ferramentas de governo eletrônico que promovam ações deliberativas e a tomada de decisão participativa (UNITED NATIONS, 2004).

\section{Apresentação e discussão dos resultados}

A fim de se atender ao objetivo deste trabalho, qual seja, analisar-se o relacionamento entre governo eletrônico e desenvolvimento econômico e humano, foram utilizados parâmetros de comparação complementares: médias das variáveis; agrupamentos regionais; indicadores de desenvolvimento econômico (renda per capita e grupos econômicos); e indicadores de desenvolvimento humano: Índice de Desenvolvimento Humano (IDH); Índice de Desenvolvimento Humano de Não Rendimento (IDH-NR); e Índice de Desenvolvimento Humano Ajustado à Desigualdade (IDH-D), os quais serão detalhados a seguir.

A fim de se realizar comparações continentais entre blocos de países, este trabalho adotou o critério de agrupamento oriundo da classificação da United Nations Statistics Division ${ }^{3}$. De acordo com essa classificação, os 193 países membros da ONU são divididos em cinco continentes (com as respectivas subdivisões internas a cada bloco): África (54 países), Américas (35 países), Ásia (47 países), Europa (43 países) e Oceania (14 países).

O primeiro indicador de desenvolvimento econômico usado como parâmetro assessório desta pesquisa foi a taxonomia elaborada pelo Banco Mundial, que classifica os países de acordo com a sua renda nacional bruta per capita (ano base 2012, com dados disponíveis para 185 países), calculada utilizando-se o World Bank Atlas Method ${ }^{4}$. Empregando-se essa metodologia, os países se dividem em quatro grupos: renda baixa (igual ou inferior a US\$1.005); renda média baixa (entre US\$

\footnotetext{
${ }^{3}$ Maiores detalhes podem ser obtidos a partir do sítio: http://unstats.un.org/unsd/methods/m49/m49regin htm.

${ }^{4}$ Outros pormenores estão disponíveis no sítio: http://data.worldbank.org/about/country-classifications.
} 
1.006 e 3.975); renda média alta (entre US\$3.976 e 12.275); e renda alta (igual ou superior a US\$12.276).

O segundo indicador de desenvolvimento econômico utilizado como parâmetro complementar desta pesquisa foi a convenção também adotada pela United Nations Statistics Division ${ }^{5}$, que agrupa os países da seguinte forma: países desenvolvidos (Japão, na Ásia; Canadá e EUA, nas Américas; Austrália e Nova Zelândia, na Oceania; e todo o continente europeu); países em desenvolvimento (África; Américas, exceto América do Norte; Ásia, exceto Japão; e Oceania, exceto Austrália e Nova Zelândia); e países menos desenvolvidos (grupo de 48 países, entre os quais 33 se encontram na África; 9 na Ásia; 5 na Oceania; e 1 nas Américas).

Por fim, esta pesquisa utilizou como parâmetros de comparação complementares os seguintes indicadores multidimensionais de desenvolvimento humano desenvolvidos pelo PNUD: Índice de Desenvolvimento Humano (IDH) (ano base 2012, com dados disponíveis para 185 países); Índice de Desenvolvimento Humano de Não Rendimento (IDH-NR) (ano base 2012, com dados disponíveis para 185 países); e Índice de Desenvolvimento Humano Ajustado à Desigualdade (IDH-D) (ano base 2012, com dados disponíveis para 132 países).

O IDH é composto por três dimensões básicas: uma vida longa e saudável (expectativa de vida ao nascer); o conhecimento (média de anos de escolaridade); e um padrão de vida digno (renda nacional bruta per capita). O IDH-NR, por sua vez, corresponde apenas às dimensões de uma vida longa e saudável e do conhecimento. Já o IDH-D baseia-se em um grupo de indicadores compostos sensíveis à distribuição proposto por Foster, Lopez-Calva e Szekely (2005), seguindo a concepção de medidas de desigualdade elaboradas por Atkinson (1970). Esse índice é o resultado de uma média geométrica de médias geométricas, calculadas em separado para cada dimensão em relação à população total. Dessa forma, o IDH-D exprime as desigualdades nas dimensões do IDH, descontando o valor médio de cada dimensão de acordo com o seu nível de desigualdade. Esse índice seria igual ao IDH se não existisse desigualdade entre as pessoas, mas diminui em relação ao IDH à medida que a desigualdade cresce.

Nesse sentido, esse índice mede o valor efetivo do desenvolvimento humano (tomando em consideração a desigualdade), ao passo que o IDH pode ser visto como um índice do desenvolvimento humano potencial que poderia ser alcançado se não existisse desigualdade. De acordo com essa metodologia, os países podem ser enquadrados em um dos seguintes grupos: desenvolvimento humano baixo (índice inferior a 0,535); desenvolvimento humano médio (índice entre 0,535

${ }_{5}^{5}$ Maiores detalhes podem ser obtidos a partir do sítio: http://unstats.un.org/unsd/methods/m49/m49regin. htm. 
e 0,710); desenvolvimento humano elevado (índice acima de 0,710 e abaixo de 0,800); e desenvolvimento humano muito elevado (índice superior a 0,800) (United nations Development Programme, 2013). A Tabela 1, a seguir, sintetiza quatro parâmetros complementares utilizados no exame individual das variáveis de pesquisa: agrupamentos regionais; renda per capita; critério de desenvolvimento econômico e classificação de desenvolvimento humano.

Tabela 1: Síntese de parâmetros complementares utilizados na pesquisa

\begin{tabular}{c|c|c|c|c|c|c|c|c|c|c|c}
\hline \multirow{2}{*}{ Região } & \multicolumn{4}{|c|}{$\begin{array}{c}\text { Taxonomia de } \\
\text { Renda per capita }\end{array}$} & \multicolumn{3}{c|}{$\begin{array}{c}\text { Critério de } \\
\text { Desenvolvimento } \\
\text { Econômico }\end{array}$} & \multicolumn{3}{c}{$\begin{array}{c}\text { Classificação de } \\
\text { Desenvolvimento Humano }\end{array}$} \\
\cline { 2 - 15 } & A & MA & MB & B & PD & PED & PMD & MA & A & M & B \\
\hline África & 6 & 8 & 23 & 16 & 0 & 20 & 33 & 1 & 4 & 10 & 37 \\
\hline Américas & 12 & 19 & 4 & 0 & 2 & 32 & 1 & 5 & 19 & 10 & 1 \\
\hline Ásia & 15 & 16 & 14 & 1 & 1 & 37 & 9 & 8 & 13 & 19 & 6 \\
\hline Europa & 32 & 8 & 1 & 0 & 43 & 0 & 0 & 30 & 10 & 1 & 0 \\
\hline Oceania & 2 & 3 & 6 & 0 & 2 & 7 & 5 & 2 & 1 & 6 & 2 \\
\hline Mundo & 67 & 54 & 48 & 16 & 48 & 96 & 48 & 46 & 47 & 46 & 46 \\
\hline
\end{tabular}

Legenda: taxonomia de renda per capita: A: alta; MA: média alta; MB: média baixa; B: baixa. Critério de desenvolvimento econômico: PD: países desenvolvidos; PED: países em desenvolvimento; PMD: países menos desenvolvidos. Classificação de desenvolvimento humano: MA: muito alto; A: alto; M: médio; B: baixo. Fonte: elaborada pelo autor com base em United Nations Development Programme (2013).

\section{E-Government Development Index}

Em termos regionais, conforme pode ser constatado a partir da análise da Tabela 2, mostrada a seguir, a Europa $(0,7188)$ apresenta o maior grau de desenvolvimento do governo eletrônico, seguida pelas Américas $(0,5402)$, ultrapassando, em ambos os casos, a média mundial $(0,4896)$.

Tabela 2: Médias regionais do EGDI e de seus componentes

\begin{tabular}{c|c|c|c|c}
\hline Região & EGDI & $\begin{array}{c}\text { Serviços } \\
\text { Online }\end{array}$ & $\begin{array}{c}\text { Infraestrutura } \\
\text { de Telecomu- } \\
\text { nicações }\end{array}$ & $\begin{array}{c}\text { Capital } \\
\text { Humano }\end{array}$ \\
\hline África & 0,2790 & 0,2588 & 0,1094 & 0,5034 \\
\hline Américas & 0,5402 & 0,4647 & 0,3602 & 0,7958 \\
\hline Ásia & 0,4991 & 0,4879 & 0,2818 & 0,7278 \\
\hline Europa & 0,7188 & 0,6189 & 0,6460 & 0,8916 \\
\hline Oceania & 0,4240 & 0,2754 & 0,2211 & 0,7754 \\
\hline Mundo & 0,4896 & 0,4343 & 0,3245 & 0,7173 \\
\hline
\end{tabular}

Fonte: Elaborada pelos autores com base em United Nations (2012). 
Esses resultados refletem uma longa história de altos níveis de educação (componente Capital Humano do EGDI) conjugados com uma história mais recente de ampla disseminação tecnológica (componente Infraestrutura de Telecomunicações do EGDI) e disponibilização de informações e serviços eletrônicos por parte do governo (componente Serviços Online do EGDI). No outro extremo, encontram-se a África $(0,2790)$ e a Oceania $(0,4240)$, ambos abaixo da média mundial. $O$ continente asiático $(0,4991)$ se posiciona levemente acima do valor de referência internacional.

O Gráfico 1, exibido abaixo, por sua vez, evidencia que o componente Capital Humano é o mais desenvolvido nos cinco continentes; o menos desenvolvido é a Infraestrutura de Telecomunicações, exceto na Europa. Uma possível explicação para esse fato reside no alto custo de implantação da infraestrutura de TIC, que se reflete, atualmente, no estágio incipiente de disseminação das conexões de banda larga (subcomponente do indicador de infraestrutura) no mundo (apenas $8,73 \%$ ).

\section{Gráfico 1: Médias regionais do EGDI e de seus componentes}

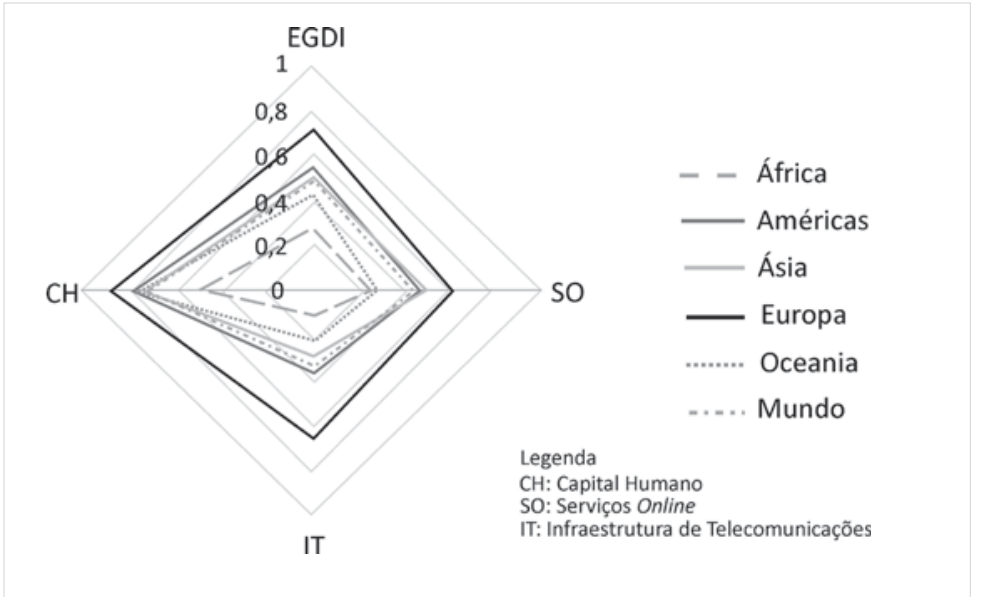

Fonte: Elaborado pelo autor com base em United Nations (2012).

Considerando-se a taxonomia de renda per capita, constata-se uma forte correlação com o $\operatorname{EGDI}(r=0,731)$. Entretanto, entre os 20 países mais bem posicionados em função do indicador de desenvolvimento do governo eletrônico, pouco mais da metade (12 países) também está no estrato mais elevado em termos de renda per capita. O líder do ranking do EGDI, Coreia do Sul $(0,9283)$, ocupa apenas a 26a posição em termos de renda per capita (US\$28.231); a Holanda $(0,9125)$, vice-líder do EGDI, ocupa apenas a 11a posição segundo a renda per capita (US\$37.282). O líder do ranking de renda per capita, o Catar (87.478), por seu turno, ocupa a modesta 48 a posição em função do $\operatorname{EGDI}(0,6405)$. No outro extremo, verifica-se que, entre os 30 países pior ordenados em função do EGDI, 
todos, exceções feitas ao Timor-Leste e à Líbia, se enquadram nas categorias de renda baixa ou média baixa. Nota-se que há, também, países bem posicionados quanto à renda per capita e mal posicionados quanto ao EGDI, tais como Seychelles e Guiné Equatorial, respectivamente 36ㅇ e 39 colocados segundo a renda e 84 e e 151 colocados de acordo com o EGDI.

Observando-se o Gráfico 2, verifica-se que há uma nítida separação entre países pertencentes a três grupos. O primeiro, mais disperso (destaque na cor azul), é composto de casos acima da média do EGDI $(0,4896)$ e renda per capita alta, igual ou superior a US\$12.276. O segundo grupo, mais concentrado que o primeiro (realce na cor laranja), tem países também acima da média do EGDI, mas com renda per capita de até US\$12.275, ou seja, variando de baixa a média alta. O terceiro, o mais concentrado dos três e também mais agrupado em torno da linha de tendência da correlação, é integrado por casos igualmente com renda de baixa a média alta, mas abaixo da média do EGDI.

\section{Gráfico 2: Relação entre EGDI e renda per capita}

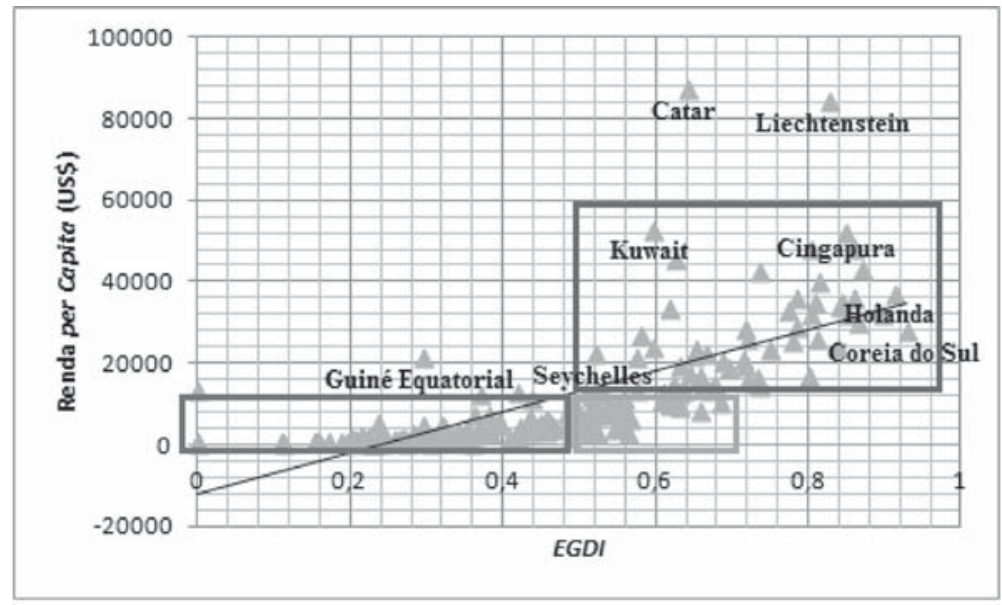

Fonte: Elaborado pelo autor com base em United Nations (2012).

Quanto ao critério de agrupamento econômico, constata-se, pela análise da Tabela 3, mostrada a seguir, que os países desenvolvidos apresentam um EGDI $(0,7329)$ equivalente a mais de um triplo daquele encontrado nos países menos desenvolvidos $(0,2420)$. Os países em desenvolvimento, por seu turno, apresentam uma média do $\operatorname{EGDI}(0,4865)$ bastante próxima da média internacional $(0,4896)$. Quando se considera apenas o componente Infraestrutura de Telecomunicações, a discrepância encontrada é bem mais expressiva: os países desenvolvidos ostentam uma média quase 10 vezes maior do que aquela dos países menos desenvolvidos. 
Tabela 3: Médias do EGDI e de seus componentes em função de grupos econômicos

\begin{tabular}{l|c|c|c|c}
\hline Grupo Econômico & EGDI & $\begin{array}{c}\text { Serviços } \\
\text { Online }\end{array}$ & $\begin{array}{c}\text { Infraestrutura } \\
\text { de } \\
\text { Telecomunicações }\end{array}$ & $\begin{array}{c}\text { Capital } \\
\text { Humano }\end{array}$ \\
\hline Países Desenvolvidos & 0,7329 & 0,6503 & 0,6509 & 0,8974 \\
\hline $\begin{array}{l}\text { Países em } \\
\text { Desenvolvimento }\end{array}$ & 0,4865 & 0,4311 & 0,2860 & 0,7553 \\
\hline $\begin{array}{l}\text { Países Menos } \\
\text { Desenvolvidos }\end{array}$ & 0,2420 & 0,2143 & 0,0685 & 0,4575 \\
\hline Mundo & 0,4896 & 0,4343 & 0,3245 & 0,7173 \\
\hline
\end{tabular}

Fonte: Elaborada pelos autores com base em United Nations (2012).

O Gráfico 3, apresentado em seguida, evidencia as cizânias ocorridas entre os componentes formadores do EGDI. Independentemente do grupo econômico considerado, o componente Capital Humano é aquele que exibe o maior desenvolvimento. Por outro lado, o componente Infraestrutura de Telecomunicações apresenta a menor média nos países em desenvolvimento e nos países menos desenvolvidos. Constatação semelhante foi feita anteriormente quando se analisaram o EGDI e seus componentes em função de agrupamentos regionais. Nos países desenvolvidos, por sua vez, o componente Serviços Online apresenta uma média ligeiramente inferior à Infraestrutura de Telecomunicações.

\section{Gráfico 3: Médias do EGDI e de seus componentes em função de grupos econômicos}

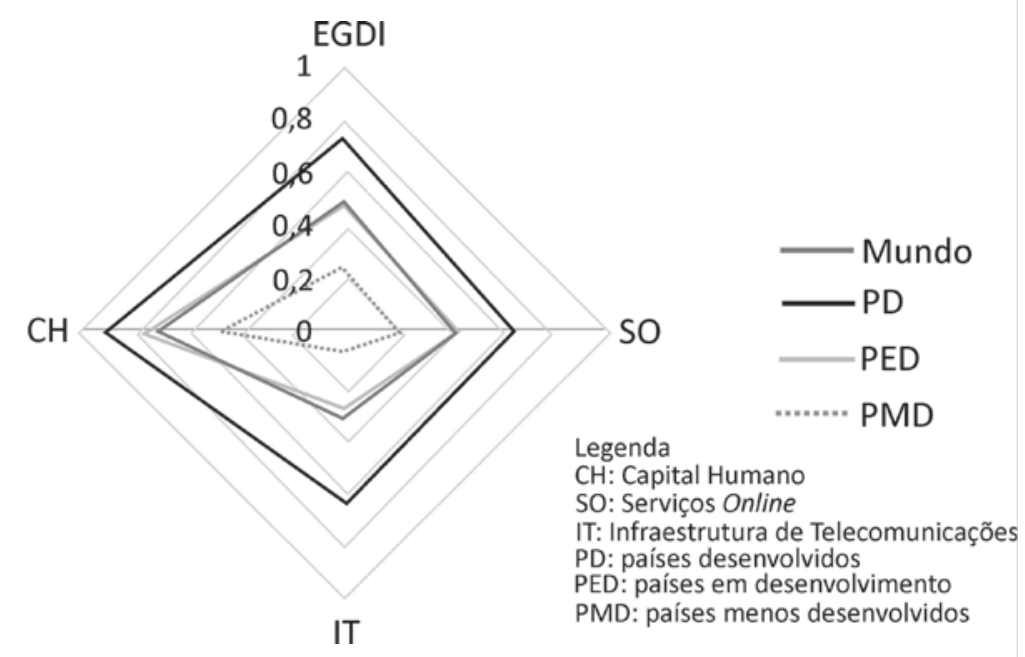

Fonte: Elaborado pelos autores com base em United Nations (2012). 
Segundo a classificação de desenvolvimento humano, levando-se em consideração o Índice de Desenvolvimento Humano (IDH), verifica-se uma correlação significativa com o EGDI $(r=0,916)$. Entre os 46 países considerados de desenvolvimento humano muito alto (ou seja, aqueles que ostentam índices acima de 0,8), todos apresentam EGDI superior à média. Essa constatação pode ser visualizada no Gráfico 4, apresentado a seguir, em destaque na cor vermelha. Por outro lado, entre os 46 países de médio desenvolvimento humano (todos aqueles com índices entre 0,710 e 0,535), o EGDI se apresenta acima da média em apenas 11 países. Entre os 46 países considerados de baixo desenvolvimento humano (todos aqueles com índices abaixo de 0,535), nenhum apresenta EGDI acima da média.

Quando se considera apenas a classificação do IDH de Não Rendimento (IDH-NR), constata-se uma correlação semelhante àquela observada quando da comparação entre IDH e EGDI, embora levemente inferior $(r=0,896)$, o que se confirma pela análise das linhas de tendências superiores, praticamente paralelas, mostradas no Gráfico 4. Cumpre notar, no entanto, que, para os mesmos valores de EGDI, os valores do IDH-NR se mostram ligeiramente superiores àqueles do IDH.

\section{Gráfico 4: Relação entre o EGDI e indicadores de desenvolvimento humano}

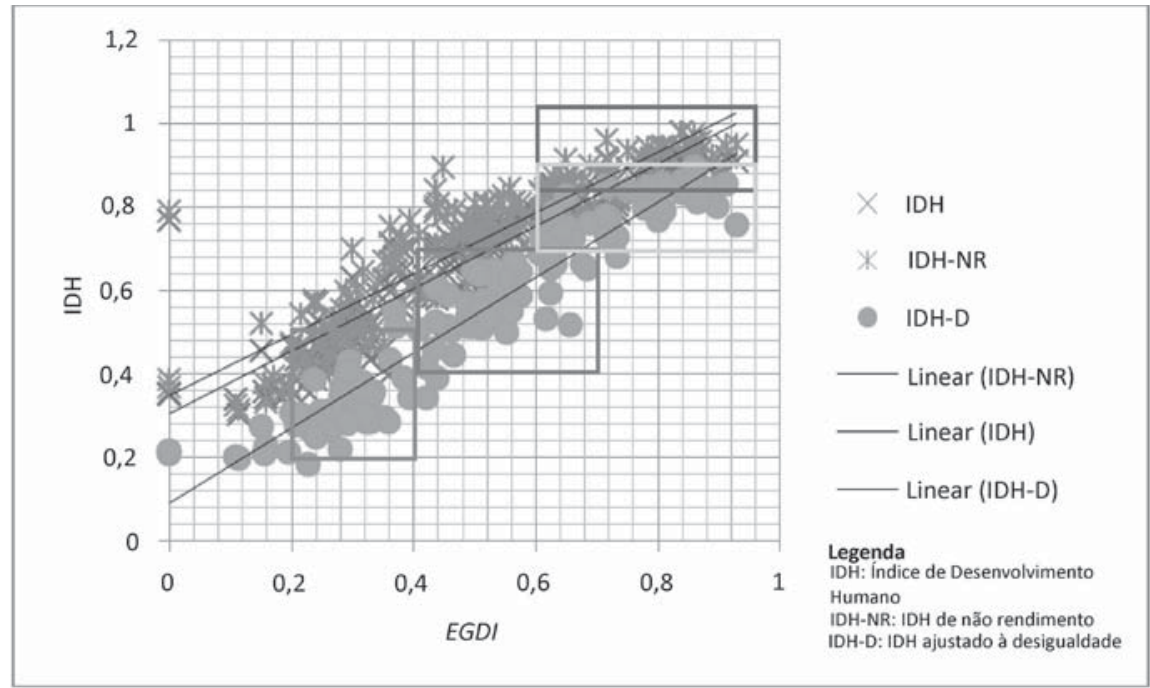

Fonte: Elaborado pelos autores com base em United Nations (2012).

A classificação do IDH Ajustado à Desigualdade (IDH-D), por sua vez, mostra algumas diferenças em relação às duas análises precedentes. Em primeiro lugar, a partir da observação do Gráfico 4, nota-se que a linha de tendência inferior se encontra mais inclinada do que as descritas anteriormente, o que reflete um maior grau de correlação do EGDI com o IDH-D $(r=0,949)$, quando comparado com os outros dois indicadores de desenvolvimento humano (IDH e IDH-NR). 
Em segundo lugar, também a partir da análise do Gráfico 4, constatam-se aglomerações de países em três grupos. O primeiro, destacado na cor verde, é composto por países de EGDI abaixo da média e desenvolvimento humano baixo, inferiores a 0,535. O segundo agrupamento de países, destacado na cor violeta, é formado por países com EGDI em torno da média (entre 0,4 e 0,7) e desenvolvimento humano médio, variando entre 0,535 e 0,710. $O$ terceiro e último conjunto de países, destacado na cor rosa, é constituído por países no mais alto patamar do EGDI (acima da média) e desenvolvimento humano alto ou muito alto (índice acima de 0,710 ).

\section{Serviços online}

Pela análise da Tabela 4, que agrupa os países por regiões, nota-se que a Europa $(0,6189)$ detém o nível mais elevado de serviços online, em todos quatro estágios do modelo de maturidade, repetindo a liderança verificada anteriormente em termos do EGDI. Em seguida vêm a Ásia $(0,4880)$ e as Américas $(0,4648)$, com médias ligeiramente superiores à mundial $(0,4343)$.

Tabela 4: Médias regionais do Índice de Serviços Online e de seus componentes

\begin{tabular}{|c|c|c|c|c|c|c|}
\hline Região & \multirow{2}{*}{$\begin{array}{c}\text { Serviços } \\
\text { Online }\end{array}$} & $\begin{array}{c}\text { Estágio I } \\
(\%)\end{array}$ & $\begin{array}{l}\text { Estágio II } \\
(\%)\end{array}$ & $\begin{array}{c}\text { Estágio III } \\
(\%)\end{array}$ & $\begin{array}{c}\text { Estágio IV } \\
(\%)\end{array}$ & $\begin{array}{c}\text { Total } \\
(\%)\end{array}$ \\
\hline $\begin{array}{c}\text { Peso Relativo } \\
\text { dos Estágios }\end{array}$ & & 7 & 24 & 30 & 39 & 100 \\
\hline África & 0,2567 & 66 & 31 & 7 & 21 & 22 \\
\hline Américas & 0,4648 & 86 & 53 & 27 & 36 & 41 \\
\hline Ásia & 0,4880 & 85 & 51 & 32 & 38 & 43 \\
\hline Europa & 0,6189 & 96 & 66 & 45 & 46 & 54 \\
\hline Oceania & 0,2754 & 61 & 34 & 14 & 20 & 24 \\
\hline Mundo & 0,4343 & 81 & 48 & 26 & 33 & 38 \\
\hline
\end{tabular}

Fonte: Elaborada pelos autores com base em United Nations (2012).

O Gráfico 5 evidencia que o componente dos serviços online relativo aos serviços informacionais emergentes (Estágio I) é o mais desenvolvido, não importando a região; esse achado pode ser explicado pela constatação de que o primeiro passo na oferta de serviços públicos eletrônicos (disponibilização de informações) é uma tarefa relativamente simples e de baixo custo. Por outro lado, os serviços transacionais (Estágio III) é o que apresenta o menor desenvolvimento; essa fase é mais complexa e depende de fatores estruturais, como o grau de desenvolvimento do sistema financeiro dos países, e também de um marco regulatório, no que tange à segurança e privacidade dos usuários de serviços (UNITEd NATIONS, 2012). 


\section{Gráfico 5: Médias regionais do Índice de Serviços Online e de seus componentes}

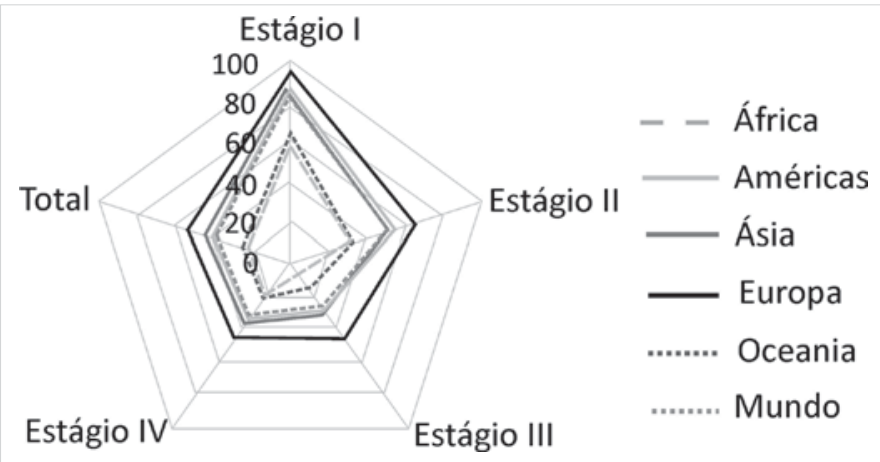

Fonte: Elaborado pelos autores com base em United Nations (2012).

Examinando-se o critério de renda per capita, verifica-se que há forte correlação com a variável de Serviços Online ( $r=0,661)$, muito embora menor do aquela apurada em relação ao EGDI. Levando-se em consideração os 40 países líderes do ranking de serviços online, apenas 4 deles não se enquadram na classificação de alta renda. No entanto, entre os 20 países mais bem ranqueados em termos do Indicador de Serviços Online, apenas metade também ocupa uma das 20 primeiras posições em função da renda per capita. Por outro lado, quando se consideram os 30 países pior ordenados em função de serviços online, apenas 6 não integram as classes de renda baixa ou média baixa. Além disso, nota-se que há países bem colocados segundo a renda per capita e mal colocados em função dos serviços online, casos de Andorra e Guiné Equatorial, respectivamente situados nas 17ạ e 39a posições pela renda e situados nas 124a e 181a posições segundo o indicador de Serviços Online. Há também situações opostas, por exemplo, a Colômbia, 17a colocada em função dos serviços online e 84a colocada em função da renda.

O Gráfico 6, mostrado a seguir, destaca a existência de três grupos. O primeiro, mais disperso, destacado na cor azul, reúne países de alta renda (igual ou superior a US\$12.276) e índices de serviços online acima da média $(0,4343)$. Aqui estão contidos tanto os líderes do Indicador de Serviços Online (Cingapura, EUA e Coreia do Sul) quanto os líderes de renda per capita (Catar, Liechtenstein, Kuwait, Cingapura e Noruega). O segundo grupo, realçado em verde, um pouco mais concentrado e vinculado à linha de tendência, é composto por casos também acima da média de serviços online, mas detentores de renda per capita de baixa a média alta (até US\$ 12.275). O terceiro e último grupo, correspondente ao retângulo de cor vermelha, agrupa países igualmente de renda baixa a média alta e índices de serviços online abaixo da média internacional. 


\section{Gráfico 6: Relação entre Serviços Online e renda per capita}

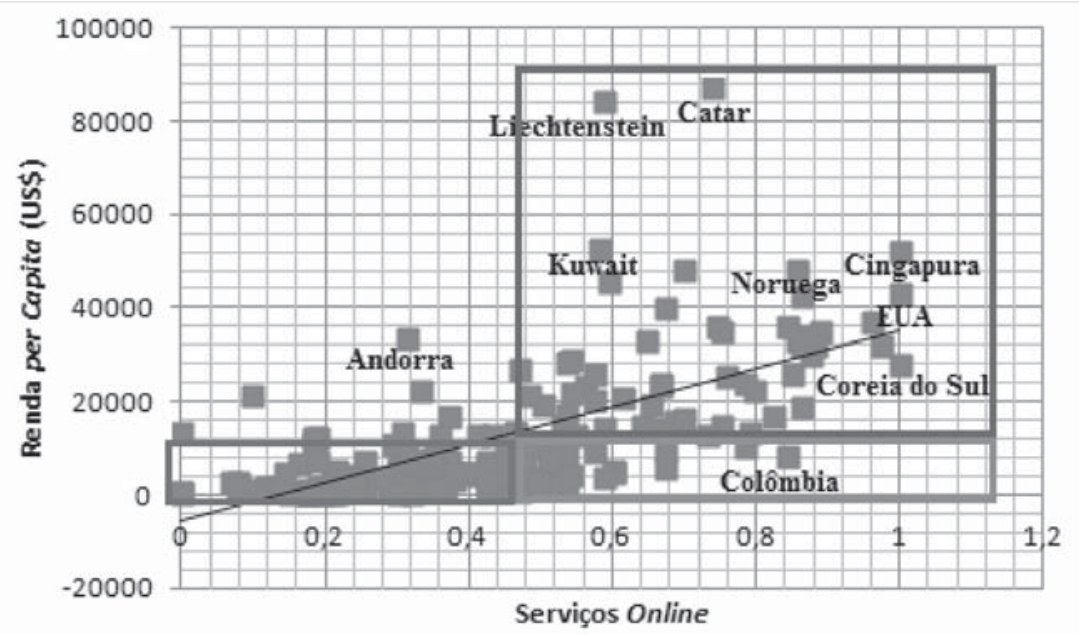

Fonte: Elaborado pelos autores com base em United Nations (2012).

O comportamento da variável Serviços Online apresenta semelhanças ao que foi constatado anteriormente com o EGDI, quando confrontado com o parâmetro de agrupamento econômico. Os dados da Tabela 5, logo abaixo, mostram que os países desenvolvidos exibem um Índice de Serviços Online $(0,6503)$ mais que três vezes superior àquele aferido nos países menos desenvolvidos $(0,2143)$. Já os países em desenvolvimento exibem uma média $(0,4311)$ análoga à mundial $(0,4343)$.

Tabela 5: Médias: Serviços Online e seus componentes em função de grupos econômicos

\begin{tabular}{|c|c|c|c|c|c|c|}
\hline Grupo Econômico & Serviços & $\begin{array}{c}\text { Estágio I } \\
(\%)\end{array}$ & $\begin{array}{c}\text { Estágio } \\
\text { II (\%) }\end{array}$ & $\begin{array}{l}\text { Estágio } \\
\text { III (\%) }\end{array}$ & $\begin{array}{l}\text { Estágio } \\
\text { IV (\%) }\end{array}$ & $\begin{array}{c}\text { Total } \\
(\%)\end{array}$ \\
\hline $\begin{array}{l}\text { Peso Relativo dos } \\
\text { Estágios }\end{array}$ & Online & 7 & 24 & 30 & 39 & 100 \\
\hline Países desenvolvidos & 0,6503 & 96 & 68 & 49 & 49 & 57 \\
\hline $\begin{array}{l}\text { Países em } \\
\text { desenvolvimento }\end{array}$ & 0,4311 & 83 & 48 & 24 & 34 & 38 \\
\hline $\begin{array}{l}\text { Países menos } \\
\text { desenvolvidos }\end{array}$ & 0,2143 & 60 & 27 & 5 & 17 & 19 \\
\hline Mundo & 0,4343 & 81 & 48 & 26 & 33 & 38 \\
\hline
\end{tabular}

Fonte: Elaborada pelos autores com base em United Nations (2012). 
A partir do Gráfico 7 mostrado abaixo, observa-se uma similaridade com aquilo que foi descrito anteriormente quando se analisaram as variações dos componentes do Indicador de Serviços Online em função de agrupamentos regionais: não importando o grupo econômico considerado, o componente que se refere aos serviços informacionais emergentes (Estágio I) se mostra mais desenvolvido do que os demais. Por ouro lado, o componente que se refere aos serviços transacionais (Estágio III) alcança percentuais menores nos países em desenvolvimento e também nos menos desenvolvidos. Já nos países desenvolvidos, constata-se que os serviços transacionais juntamente com os serviços conectados apresentam os menores percentuais.

Gráfico 7: Médias: Serviços Online e seus componentes em função de grupos econômicos

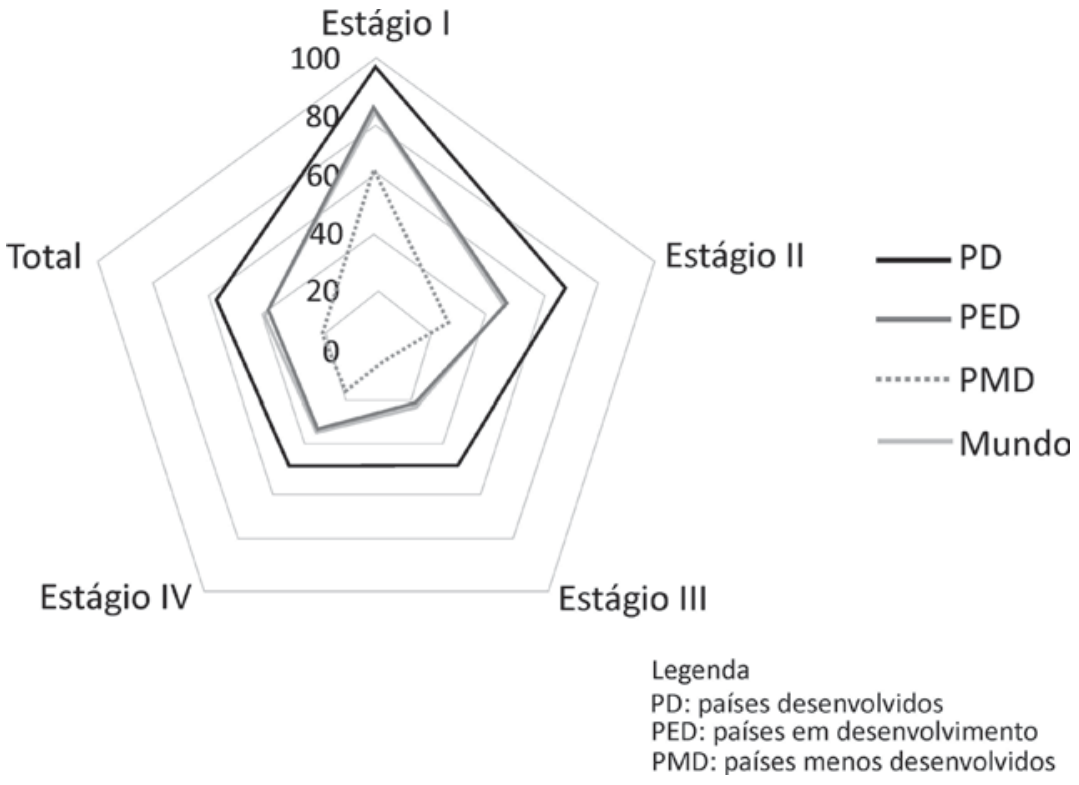

Fonte: Elaborado pelo autor com base em United Nations (2012)

De acordo com a categorização de desenvolvimento humano, quando se considera o IDH, constata-se uma forte correlação com o Índice de Serviços Online $(r=0,741)$, muito embora bem menor do que aquela observada entre o EGDI e o IDH. Quando se analisam os 46 países de desenvolvimento humano muito alto, verifica-se que apenas 3 casos apresentam valores do indicador de Serviços Online inferiores à média. Dos 47 países de desenvolvimento humano alto, por sua vez, 19 apresentam índices de serviços online abaixo da média. No outro extremo, ao se avaliar o grupo de 46 países de médio desenvolvimento humano, percebe-se que 
o indicador de Serviços Online apresenta valores acima da média em cerca de um terço (16 países). Por fim, entre os 46 países de baixo desenvolvimento humano, somente 2 ostentam índices de serviços online acima da média.

Ao se cotejar o indicador de Serviços Online com o IDH-NR, por seu turno, constatase uma correlação $(r=0,709)$ ligeiramente inferior à observada anteriormente com o IDH. Trata-se, também, de uma correlação bastante inferior àquela observada entre o EGDI e o IDH-NR. A seguir, o Gráfico 8 confirma esses achados ao mostrar linhas de tendências superiores com grau de inclinação semelhante, embora o IDH-NR se mostre suavemente elevado em relação ao IDH para um mesmo Índice de Serviços Online.

\section{Gráfico 8: Relação entre Serviços Online e Indicadores de Desenvolvimento Humano}

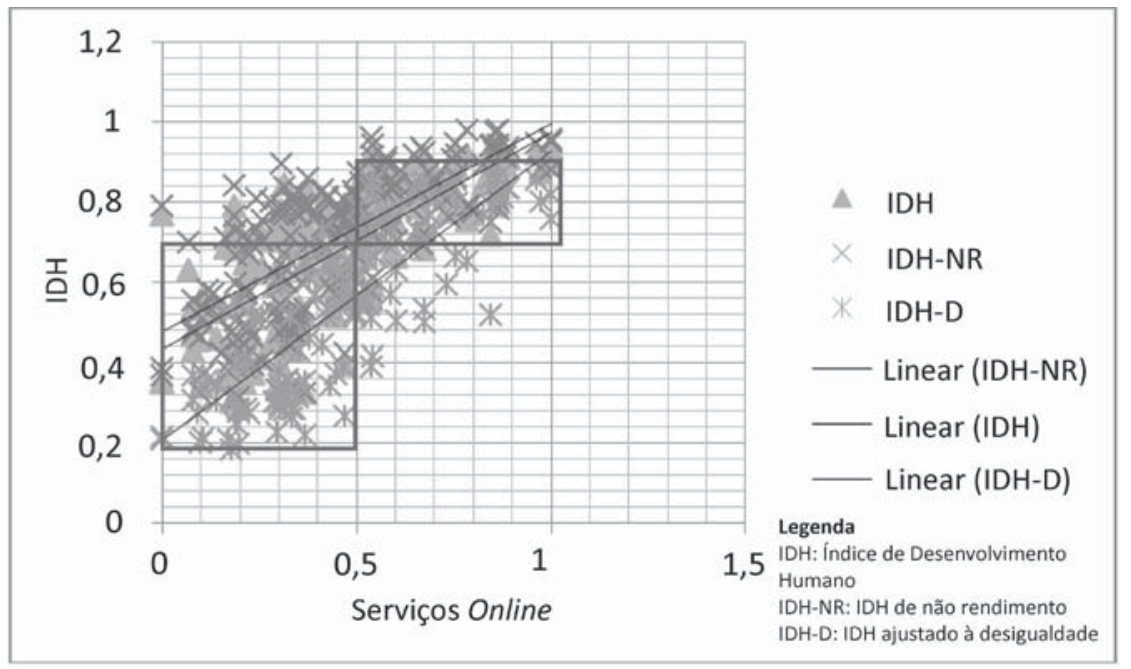

Fonte: Elaborado pelos autores com base em United Nations (2012).

A partir da análise do Gráfico 8, é possível comparar as correlações entre o indicador de Serviços Online e os três indicadores de desenvolvimento humano: IDH; IDH-NR; e IDH-D. A primeira constatação que se faz é que o grau de correlação do Índice de Serviços Online com o IDH-D é mais significativo $(r=0,805)$, achado semelhante ao ocorrido quando se comparou o EGDI com os indicadores de desenvolvimento humano. A segunda constatação que se faz é que não há agrupamentos de países tão nítidos, como se observou anteriormente na comparação com o EGDI. Entretanto, é possível, analisando-se o Gráfico 8, verificar dois agrupamentos de casos. No destaque na cor vermelha, enquadram-se aqueles detentores de índices de serviços online abaixo da média, correspondendo a níveis baixo e médio de desenvolvimento humano, ou seja, até 0,710 . Já o destaque na cor 
azul realça o grupo de países possuidores de índices de serviços online superiores à média, ao que correspondem graus de alto e muito alto desenvolvimento humano, acima de 0,710 .

\section{Participação eletrônica}

Os dados da Tabela 6 mostram a liderança da Europa $(0,3482)$ em termos de Participação Eletrônica como grupo regional, repetindo o que foi observado anteriormente quando da análise do EGDI e dos Serviços Online. Na sequência, vêm Ásia $(0,2738)$ e Américas $(0,2579)$, que ostentam médias acima da internacional $(0,2236)$. Oceania $(0,1147)$ e África $(0,0828)$, por outro lado, detêm médias bem abaixo do mundo.

Tabela 6: Médias regionais: Participação Eletrônica, EGDI e Serviços Online

\begin{tabular}{c|c|c|c}
\hline Região & $\begin{array}{c}\text { Participação } \\
\text { Eletrônica }\end{array}$ & EGDI & Serviços Online \\
\hline África & 0,0828 & 0,2790 & 0,2588 \\
\hline Américas & 0,2579 & 0,5402 & 0,4647 \\
\hline Ásia & 0,2738 & 0,4991 & 0,4879 \\
\hline Europa & 0,3482 & 0,7188 & 0,6189 \\
\hline Oceania & 0,1147 & 0,4240 & 0,2754 \\
\hline Mundo & 0,2236 & 0,4896 & 0,4343 \\
\hline
\end{tabular}

Fonte: Elaborada pelos autores com base em United Nations (2012).

Pela análise do Gráfico 9 fica claro que a variável Participação Eletrônica apresenta os menores índices quando comparada com as outras duas variáveis de pesquisa relativas ao governo eletrônico, EGDI e Serviços Online. Tal achado pode ser explicado pela constatação de que o engajamento da sociedade é um passo que vai além da disponibilização de informações aos cidadãos por parte dos governos. A participação eletrônica efetiva requer que os governos atuem proativamente como promotores de serviços públicos eletrônicos concebidos em função das necessidades dos cidadãos; esses, por sua vez, deixam de ser destinatários passivos de informação e tornam-se parceiros ativos nessa nova forma de interação Estadosociedade (UNITED NATIONS, 2012). 


\section{Gráfico 9: Médias regionais: Participação Eletrônica, EGDI e Serviços Online}

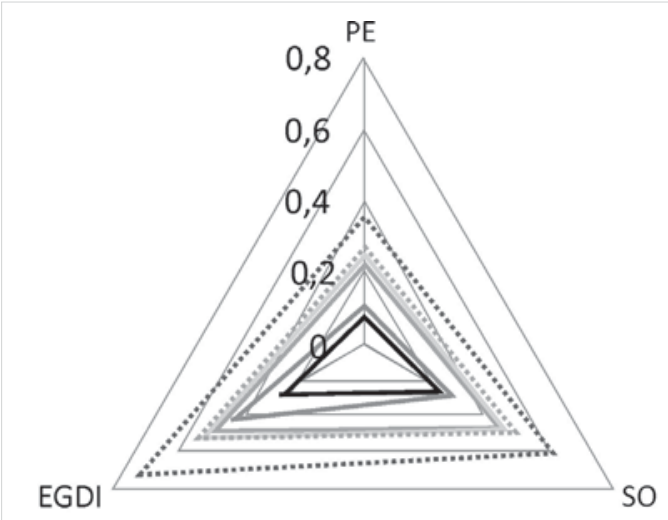

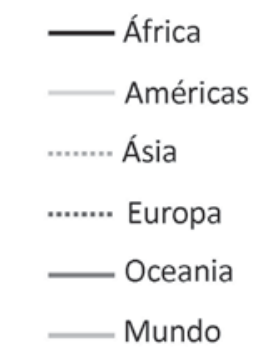

Legenda

PE: Participação

Eletrônica

SO: Serviços Online

EGDI: E-government

Development Index

Fonte: Elaborado pelo autor com base em United Nations (2012).

Constata-se que existe uma forte correlação $(r=0,575)$ entre renda per capita e Participação Eletrônica; no entanto, em grau menor do que aquelas constatadas em relação ao EGDI $(r=0,731)$ e aos Serviços Online $(r=0,661)$. Entre os 40 países que lideram o ranking de participação eletrônica, somente cerca de um quarto (9) não estão classificados como países de alta renda. Entretanto, quando se comparam os 20 países mais bem ordenados em função da renda per capita, apenas metade (10) também ocupa uma posição entre os 20 países mais bem classificados em termos da participação eletrônica. No outro extremo, entre os 30 países pior ordenados em termos da participação eletrônica, há um único representante do grupo de países de alta renda, a Líbia.

Analisando-se o Gráfico 10, exibido a seguir, constata-se, inicialmente, uma aglomeração situada no retângulo inferior esquerdo (destaque em vermelho), formada por países detentores de renda per capita de baixa a média alta (até US\$ 12.275) e participação eletrônica até o valor da média mundial. Além disso, notam-se algumas discrepâncias, como é o caso dos líderes de renda per capita Catar, Liechtenstein e Kuwait, respectivamente $22^{\circ}$, $60^{\circ}$ e e $75^{\circ}$ colocados segundo a participação eletrônica. Já o Cazaquistão, 3o colocado em participação eletrônica, ocupa a 76ạ posição de acordo com a renda per capita. No destaque em laranja, por outro lado, encontra-se o grupo mais disperso, formado por países acima da média de participação eletrônica e de alta renda (igual ou superior a US\$12.276). 0 retângulo realçado na cor amarela traz países também de alta renda per capita, mas 
com índices abaixo da média de participação eletrônica. Já o destaque na cor verde, reúne casos de renda de baixa a média alta e índices de participação eletrônica acima da média.

\section{Gráfico 10: Relação entre Participação Eletrônica e renda per capita}

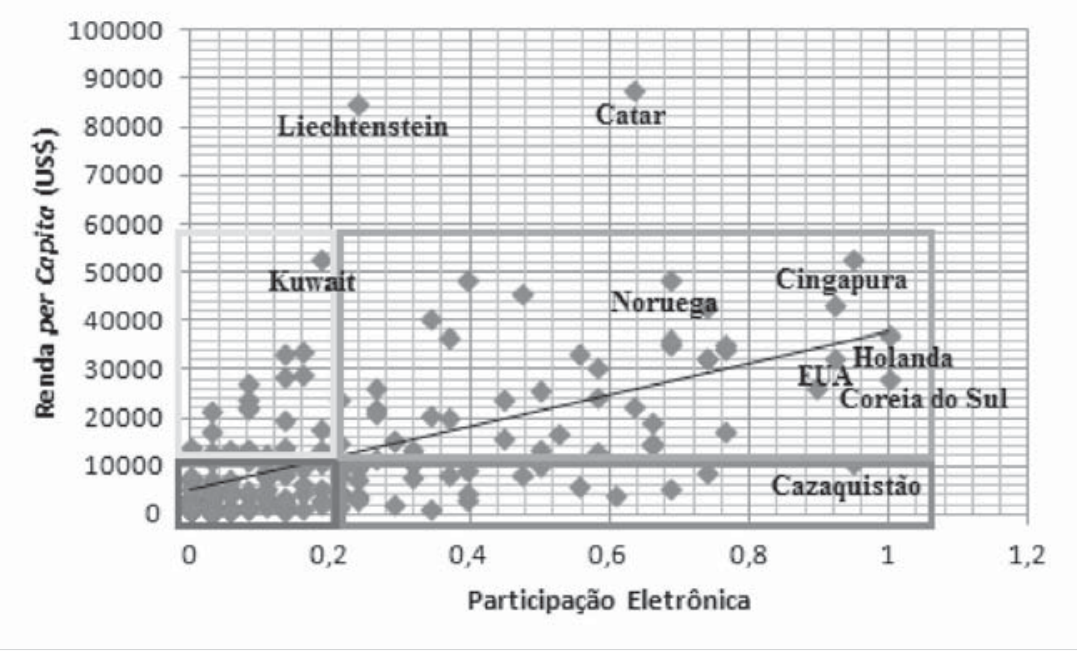

Fonte: Elaborado pelos autores com base em United Nations (2012).

A Tabela 7, apresentada abaixo, mostra que o desempenho dos indicadores de governo eletrônico apresenta similaridades quando considerado o critério de desenvolvimento econômico, ou seja: maiores índices nos países desenvolvidos; menores índices nos países menos desenvolvidos; e índices próximos à média mundial nos países em desenvolvimento. Não obstante, a variável Participação Eletrônica exibe algo peculiar quando comparada às demais: sua média nos países menos desenvolvidos $(0,0428)$ alcança somente cerca de $10 \%$ daquela observada nos países desenvolvidos $(0,3990)$.

Tabela 7: Médias dos Indicadores de Governo Eletrônico por grupos econômicos

\begin{tabular}{c|c|c|c}
\hline Grupo Econômico & $\begin{array}{c}\text { Participação } \\
\text { Eletrônica }\end{array}$ & EGDI & Serviços Online \\
\hline Países desenvolvidos & 0,3990 & 0,7329 & 0,6503 \\
\hline $\begin{array}{c}\text { Países em } \\
\text { desenvolvimento }\end{array}$ & 0,2223 & 0,4865 & 0,4311 \\
\hline $\begin{array}{c}\text { Países menos } \\
\text { desenvolvidos }\end{array}$ & 0,0428 & 0,2420 & 0,2143 \\
\hline Mundo & 0,2236 & 0,4896 & 0,4343 \\
\hline
\end{tabular}

Fonte: Elaborada pelos autores com base em United Nations (2012). 
O padrão de comportamento observado no Gráfico 11, mostrado logo abaixo, foi constatado também anteriormente quando da análise das três variáveis de pesquisa referentes ao governo eletrônico em função de agrupamentos regionais, ou seja: o EGDI se mostra sempre maior que as demais, independentemente do grupo econômico em questão; por outro lado, a Participação Eletrônica se mostra sempre inferior às demais variáveis de pesquisa. Além disso, cabe destacar que esses achados estão intimamente relacionados com a distribuição exposta anteriormente na Tabela 1, a partir da qual se constata que $68,75 \%$ dos países menos desenvolvidos se encontram no continente africano.

\section{Gráfico 11: Médias dos Indicadores de Governo Eletrônico por grupos econômicos}

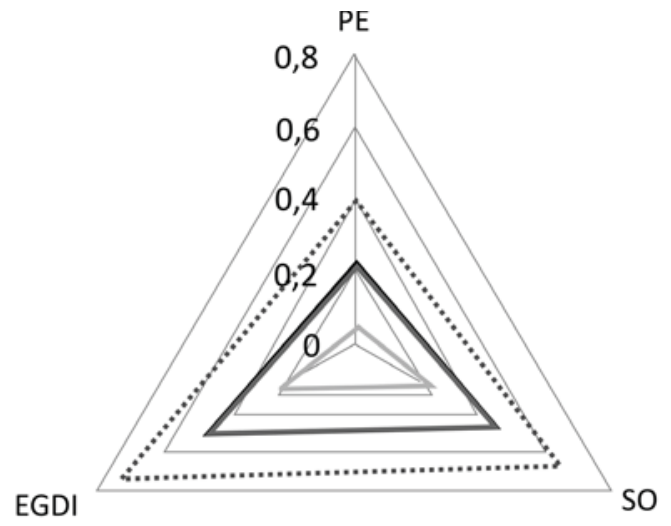

Fonte: Elaborado pelos autores com base em United Nations (2012).

\section{Legenda}

PE: Participação Eletrônica

SO: Serviços Online

EGDI: E-government

Development Index

PD: países desenvolvidos

PED: países em

desenvolvimentos

PMD: países menos

desenvolvidos

Considerando-se a classificação de desenvolvimento humano, pelo IDH inicialmente, verifica-se que existe uma forte correlação com a Participação Eletrônica $(r=0,596)$; entretanto, bastante inferior à constatada entre o EGDI $(r=0,916)$ e os Serviços Online $(r=0,741)$ e o IDH. Analisando-se os 46 países considerados de desenvolvimento humano muito alto, nota-se que 35 detêm índices de participação eletrônica superiores à média mundial $(0,2236)$. Dos 47 países de desenvolvimento humano alto, por sua vez, apenas 18 apresentam índices de serviços online acima da média. Na outra extremidade da distribuição, levando-se em conta os 46 países de médio desenvolvimento humano, constatam-se 35 abaixo da média internacional. $\mathrm{E}$, entre os 46 países de baixo desenvolvimento humano, apenas a Etiópia ostenta um Índice de Serviços Online superior à média.

O grau de correlação entre a Participação Eletrônica e o IDH Ajustado à Desigualdade $(r=0,595)$ é bem semelhante ao que foi verificado anteriormente em 
relação ao IDH; seu índice é apenas sutilmente inferior. Já quando se colaciona a Participação Eletrônica com o IDH de Não Rendimento, verifica-se uma correlação $(r=0,563)$ em nível abaixo das duas notadas anteriormente. Além disso, tanto o IDH Ajustado à Desigualdade quanto o IDH de Não Rendimento apresentam graus de correlação menores com a Participação Eletrônica quando comparados com o EGDI e com os Serviços Online.

O Gráfico 12, apresentado a seguir, mostra a relação entre o indicador de Participação Eletrônica e os três indicadores de desenvolvimento humano: IDH; IDH de Não Rendimento; e IDH Ajustado à Desigualdade.

\section{Gráfico 12: Relação entre Participação Eletrônica e Indicadores de Desenvolvimento Humano}

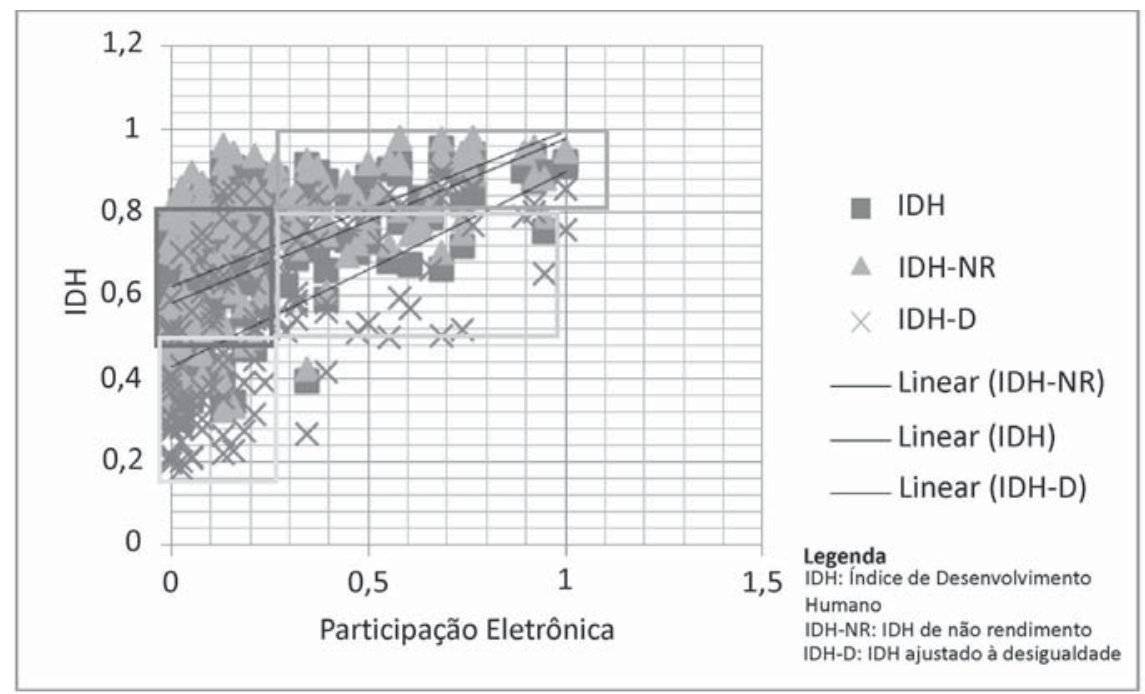

Fonte: Elaborado pelos autores com base em United Nations (2012).

A partir de sua análise, é possível visualizar quatro subgrupos: dois acima da média mundial do Índice de Participação Eletrônica; outros dois situados abaixo da média. $O$ destaque na cor laranja congrega países acima da média em Participação Eletrônica e desenvolvimento humano muito alto. O destaque na cor rosa agrega países também acima da média em Participação Eletrônica, mas com desenvolvimento humano de médio a alto. O retângulo na cor vermelha, por seu turno, agrupa países abaixo da média segundo o indicador de participação eletrônica e desenvolvimento humano médio ou alto. Por fim, o retângulo na cor amarela ajunta países igualmente abaixo da média em função do Índice de Participação Eletrônica, mas classificados como detentores de desenvolvimento humano baixo. 


\section{Conclusões}

A literatura existente sobre governo eletrônico tem, frequentemente, apontado a emergência de novas tecnologias de informação e comunicação (TIC), e seus desdobramentos, como fatores de impulso ao desenvolvimento econômico e humano. Muito embora a literatura faça referências a esse tipo de relacionamento, a realização de estudos empíricos, objetivando comprovar essas correlações, é bastante escassa. Tal constatação decorre da natureza complexa do governo eletrônico associada com seu estágio de desenvolvimento incipiente. A presente pesquisa buscou, portanto, preencher essa lacuna. Além disso, a realização de um estudo comparativo global, abordando o governo eletrônico de modo transversal, com o auxílio de diversos parâmetros de referência complementares, também veio suprir uma carência nessa área de trabalho.

A metodologia utilizada a fim de se verificar empiricamente os pressupostos deste trabalho derivou de sua abordagem dedutiva e objetiva, ou seja, lançou-se mão de uma estratégia de pesquisa de natureza quantitativa. Optou-se pela seleção de dados secundários, o que proporcionou, entre outros benefícios, a maior ênfase dispensada à análise de resultados. Além disso, ressalta-se que os dados utilizados neste estudo não se baseiam em amostras, mas em populações, o que possibilitou a obtenção de um cenário global dos fenômenos analisados.

Em primeiro lugar, verifica-se que a Europa apresenta os melhores índices de desenvolvimento do governo eletrônico, enquanto a África ostenta os piores. As posições intermediárias são ocupadas pelos demais continentes, que se alternam em função da variável considerada.

Em segundo lugar, constatam-se fortes correlações entre a renda per capita e os indicadores de governo eletrônico selecionados neste estudo. A correlação mais significativa com a renda per capita se dá com a variável EGDI e a menor com a participação eletrônica. Essa é uma contribuição importante oferecida à base de conhecimento sobre o tema em estudo.

Em terceiro lugar, quando se avaliam os grupos econômicos, verifica-se que os países desenvolvidos apresentam, sempre, os melhores índices de desenvolvimento do governo eletrônico, ao passo que os países menos desenvolvidos exibem os piores. Os países em desenvolvimento, por sua vez, ostentam índices intermediários que variam em torno das médias internacionais dos respectivos indicadores.

Em quarto lugar, também se constata que há correlações fortes entre os indicadores de desenvolvimento humano e as variáveis referentes ao governo eletrônico, em que o maior grau de associação se dá com o IDH Ajustado à Desigualdade e o menor com o IDH de Não Rendimento, exceto pela variável 
Participação Eletrônica, que apresenta a correlação com o IDH levemente superior à observada com o IDH de Não Rendimento.

Em quinto lugar, considerando-se apenas o Índice de Desenvolvimento Humano (IDH), verifica-se que o maior coeficiente de associação se dá com o EGDI, seguido de Serviços Online e Participação Eletrônica. Esse padrão é repetido quando se leva em conta o IDH de Não Rendimento. Ressalta que a quarta e quinta constatações não foram previstas na teoria existente sobre os temas de pesquisa, configurandose em relevantes contribuições teóricas.

Em sexto lugar, constata-se que a liderança mundial, segundo os rankings de governo eletrônico, é composta, maciçamente, por países europeus, classificados como desenvolvidos, considerados de alta renda e categorizados como detentores de desenvolvimento humano muito alto. Não obstante, alguns países são exceções a esse perfil, como a Coreia do Sul e Cingapura (países asiáticos pertencentes ao grupo econômico classificado como em desenvolvimento), Estados Unidos da América, Canadá, Austrália, Nova Zelândia e Japão.

Emirados Árabes Unidos e Israel são outros exemplos de perfis diversos da maioria dos líderes dos rankings internacionais, pois se trata de países em desenvolvimento, muito embora integrem as classes mais elevadas de desenvolvimento humano e renda per capita. Por fim, a presença de Cazaquistão, Bahrein e Colômbia, países da Ásia e das Américas, detentores de renda média alta e classificados como de desenvolvimento humano alto, novamente chama a atenção pela discrepância.

Em sétimo e último lugar, no que tange especificamente às variáveis relativas ao governo eletrônico, verifica-se a liderança de dois países asiáticos considerados em desenvolvimento: Coreia do Sul, primeira colocada em termos do EGDI e também do indicador de Participação Eletrônica, e Cingapura, líder do ranking do Índice de Serviços Online.

Por fim, este trabalho traz uma série de recomendações, em função de limitações intrínsecas, como tempo restrito ou delimitação do objeto de estudo, e limitações extrínsecas, como a indisponibilidade de dados. Em primeiro lugar, as análises de correlações aqui descritas poderiam ser realizadas tomando-se por indicadores bases de dados distintas das que foram selecionadas para esta pesquisa. Poderiam, por exemplo, ser utilizados indicadores nacionais sobre governo eletrônico, tais quais aqueles mantidos pelo Comitê Gestor da Internet no Brasil.

Em segundo lugar, seria possível realizar, com as mesmas variáveis desta pesquisa, estudos de corte longitudinal, com grupos menores de países, por regiões, por grupos econômicos, ou mesmo poderiam ser realizados estudos sobre casos individuais. Em terceiro, poderiam ser levados a cabo outros trabalhos empíricos, a partir dessas mesmas variáveis de análise, mas se empregando uma estratégia 
de pesquisa diversa, qual seja, qualitativa, fruto de uma abordagem indutiva e subjetiva dos fenômenos.

Em último lugar, deve-se sublinhar que algumas constatações oriundas da análise de dados desta pesquisa requerem um aprofundamento posterior, a fim de se elucidar as causas de diversas ocorrências encontradas. Por exemplo, no caso dos países que se destacam nos diversos rankings apresentados, mas que não se enquadram no perfil dominante, como é o caso da Coreia do Sul e do Canadá, seria interessante a realização de estudos individuais. Tais estudos viabilizariam um entendimento pormenorizado da realidade de cada um deles, sendo possível avaliar outros fatores como o ambiente político e a existência de projetos de governo eletrônico, independentemente de estarem em andamento ou de já terem chegado ao seu termo.

\section{Referências bibliográficas}

Alonso, L. B. N.; FernedA, E.; BragA, L. V. Governo eletrônico e políticas públicas: análise sobre $O$ uso da certificação digital no Brasil. Informação \& Sociedade: Estudos, v. 21, no 2, p. 13-24, 2011.

ANAND, S.; SEN, A. Human development and economic sustainability. World Development, v. 28, no 12, p. 2029-2049, 2000.

ATKINSON, A. On the measurement of economic inequality. Journal of Economic Theory, v. 2, no 3, p. 244-63, 1970.

BANNISTER, F.; CONNOLLY, R. The great theory hunt: does e-government really have a problem? Government Information Quarterly, v. 32, no 1, p. 1-11, 2015.

BHATNAGAR, S. E-government: from vision to implementation: a practical guide with case studies. Thousand Oaks: Sage Publications, 2004.

BRAGA, C. F. G. V.; BRAGA, L. V. Aplicação de tecnologias de informação e comunicação na contratação pública: a experiência portuguesa. Revista Brasileira de Políticas Públicas, v. 1, no 3, p. 123-143, 2011.

BRAGA, L. V. Inclusão digital: fator essencial ao progresso do governo eletrônico no Brasil. Revista de Políticas Públicas e Gestão Governamental: Res Pvblica, v. 6, no 2, p. 53-76, 2007.

. Certificação digital: a chave para um governo eletrônico seguro. Revista de Políticas Públicas e Gestão Governamental: Res Pvblica, v. 8, no 2, p. 4559, 2009.

O impacto do governo eletrônico sobre a prestação de serviços públicos no Brasil: aplicações da certificação digital. Universitas: Gestão e TI, v. 1, no 2, p. 87-102, 2011.

BRAGA, L. V. et al. O papel do governo eletrônico no fortalecimento da governança do setor público. Revista do Serviço Público, v. 59, no 1, p. 5-21, 2008. 
BoVAIRD, T. E-government and e-governance: organizational implications, options, and dilemmas. In: KHosRow-Pour, M. (Org.) Practicing e-government: a global perspective. Hershey: Idea Group Publishing, 2005. p. 43-61.

Bryman, A. Social research methods. $3^{\text {rd }}$ ed. Oxford: Oxford University Press, 2008. BURRELL, G.; MORGAN, G. Sociological paradigms and organizational analysis: elements of the sociology of corporate life. Burlington: Ashgate Publishing Limited, 1979.

BUSSELL, J. Explaining cross-national variation in government adoption of new technologies. International Studies Quarterly, v. 55, no 1, p. 267-280, 2011.

CARTER, L.; BÉLANGER, F. The utilization of e-government services: citizen trust, innovation and acceptance factors. Information Systems Journal, v. 15, no 1, p. 2-25, 2005.

CURTIN, G. G.; SOMMeR, M. H.; VIS-SOMMeR, V. The world of e-government. New York: Haworth Press, 2004.

D'Agostino, M. J. et al. A Study of e-government and e-governance: an empirical examination of municipal websites. Public Administration Quarterly, v. 35, Issue 1, p. 3-25, 2011.

DEAKINS, E. et al. Local e-government impact in China, New Zealand, Oman, and the United Kingdom. International Journal of Public Sector Management, v. 23, no 6, p. 520-534, 2010.

DUNLEAVY, P. et al. New public management is dead-long live digital-era governance. Journal of Public Administration Research and Theory, v. 16, no 3, p. 467-494, 2006.

EUROPEAN COMMUNITIES. The role of e-government for Europe's future. Brussels: Commission of the European Communities, 2003.

Ferneda, E.; Alonso, L. B. N.; Braga, L. V. Digital certification in the Brazilian e-government. Journal of Information Systems and Technology Management, v. 8, no 2, p. 331-346, 2011.

Foster, J.; López-Calva, L.; Szekely, M. Measuring the distribution of human development: methodology and an application to Mexico. Journal of Human Development and Capabilities, v. 6, no 1, p. 5-25, 2005.

GOLDFINCH, S.; GAULD, R.; BALDWIN, N. Information and communications technology use, e-government, pain and stress amongst public servants. New Technology, Work and Employment, v. 26, no 1, p. 39-53, 2011.

GRÖNLUND, Å. Electronic government: design, applications \& management. Hershey: Idea Group Publishing, 2002.

HEEKS, R.; BAILUR, S. Analyzing e-government research: perspectives, philosophies, theories, methods, and practice. Government Information Quarterly, v. 24, no 2, p. 243-265, 2007.

HIRSCHMAN, A. O. Essays in trespassing: economics to politics and beyond. Cambridge: Cambridge University Press, 1981.

Ho, A. T. Reinventing local governments and the e-government initiative. Public Administration Review, v. 62, no 4, p. 434-444, 2002. 
LARSSON, H.; GRÖNLUND, A. Future-oriented eGovernance: the sustainability concept in eGov research, and ways forward. Government Information Quarterly, Vol. 31, No. 1, p. 137-149, 2014.

LENK, K.; TRAUNMÜLLER, R. Broadening the concept of electronic government. In: PRINS, J. E. J. (Ed.). Designing e-government. $2^{\text {nd }}$ ed. Alphen aan den Rijn: Kluwer Law International, 2007. p. 9-21.

LÖFSTEDT, U. E-government - assessment of current research and some proposals for future directions. International Journal of Public Information Systems, Vol. 2005, No. 1, p. 39-52, 2005.

MEDAGLIA, R. Engaged scholarship in research on information technology in government. Information, Communication \& Society, Vol. 15, No. 2, p. 246-259, 2012.

MeHTA, L. Water and Human Development. World Development, Vol. 59, p. 59-69, 2014.

MILWARD, H. B.; SNYDER, L. O. Electronic government: linking citizens to public organizations through technology. Journal of Public Administration Research and Theory, v. 6, no 2, p. 261-275, 1996.

MISURACA, G. C. E-government 2015: exploring m-government scenarios, between ICT-driven experiments and citizen-centric implications. Technology Analysis \& Strategic Management, v. 21, no 3, p. 407-424, 2009.

MOSSE, B.; WHITLEY, E. A. Critically classifying: UK e-government website benchmarking and the recasting of the citizen as customer. Information Systems Journal, v. 19, no 2, p. 149-173, 2009.

PINA, V.; TORRES, L.; ROYO, S. Are ICTs improving transparency and accountability in the EU regional and local governments? An empirical study. Public Administration, v. 85, no 2, p. 449-472, 2007.

PoluITT, C. "Moderation in all things": international comparisons of governance quality. Financial Accountability \& Management, v. 27, no 4, p. 437-457, 2011.

ROBERTSON, S. P.; VATRAPU, R. K. Digital government. Annual Review of Information Science and Technology, v. 44, Issue 1, p. 317-364, 2010.

SEN, A. Development: which way now? The Economic Journal, Vol. 93, No. 372, p. 745-762, 1983.

SENDING, O. J.; NEUMANN, I. B. Governance to governmentality: analyzing NGOs, states, and power. International Studies Quarterly, v. 50, no 3, p. 651-672, 2006.

STAHL, B. C. The paradigm of e-commerce in e-government and e-democracy. In: HUANG, W.; SIAU, K.; WEI, K. K. Electronic government strategies and implementation. Hershey: Idea Group Publishing, 2005. p. 1-19.

TRIPATHI, R.; GUPTA, M. P.; BHATTACHARYA, J. Interoperability adoption among government and corporate portals in India: a study. Journal of Enterprise Information Management, v. 25, no 2, p. 98-122, 2012.

UNITED NATIONS. UN global e-government survey 2003. New York: Department of Economic and Social Affairs, 2003.

UN global e-government readiness report 2004: towards access for opportunity. New York: Department of Economic and Social Affairs, 2004. 
UN global e-government readiness report 2005: from e-government to e-inclusion. New York: Department of Economic and Social Affairs, 2005.

. Initiative on global e-government assessment. New York: Department of Economic and Social Affairs, 2007.

UN e-government survey 2008: from e-government to connected governance. New York: Department of Economic and Social Affairs, 2008.

UN e-government survey 2010: leveraging e-government at a time of financial and economic crisis. New York: Department of Economic and Social Affairs, 2010.

UN e-government survey 2012: e-government for the people. New York: Department of Economic and Social Affairs, 2012.

UNITED NATIONS; American Society for Public Administration. Benchmarking e-government: a global perspective. New York: United Nations Division for Public Economics and Public Administration, 2002.

United nations Development Programme. Human development report 2013. The rise of the south: human progress in a diverse world. New York: United Nations, 2013. WEERAKKODY, V. et al. E-government implementation strategies in developed and transition economies: a comparative study. International Journal of Information Management, v. 32, no 1, p. 66-74, 2012.

ZWEERS, K. Electronic government in the US: a citizen-centric approach? In: PRINS, J. E. J. (Ed.). Designing e-government. $2^{\text {nd }}$ ed. Alphen aan den Rijn: Kluwer Law International, 2007. p. 87-111.

Lamartine Vieira Braga

Doutor em Administração pela Universidade de Brasília/University of Edinburgh Business School e Professor Colaborador da Fundação Getúlio Vargas (FGV Management). Contato: lamartine.braga@gmail.com

Ricardo Corrêa Gomes

É pós-doutor pela Georgia State University (2014) e professor Associado II da Universidade de Brasília. Contato: gomesic.rg@gmail.com 